\title{
Selection of biosphere transfer parameter values for radioactive waste disposal impact assessments, a site specific approach
}

\author{
E. Leclerc-Cessac ${ }^{1}$ and N. J aubert ${ }^{2}$ \\ ${ }^{1}$ Andra, Agence Nationale de Gestion des Déchets Radioactifs, 1-7 rue Jean Monnet, \\ Châtenay-Malabry, 92298 Cedex, France, e-mail: elisabeth.leclerc@andra.fr \\ ${ }^{2}$ ISIGE, Institut Supérieur de d'Ingénierie et Gestion de l'Environnement, \\ 77350 Fontainebleau, France
}

\begin{abstract}
In order to perform radiological impact assessments of radioactive waste disposals, a compartmental model taking into account generic data for biosphere transfer parameters values is usually used. To improve its performance assessments calculations, Andra (French national radioactive waste management agency) decided to adapt this type of biosphere model to its sites conditions. On one hand, specific models have been developed such as model for ${ }^{36} \mathrm{Cl}$ based on isotopic dilution and on local stable chlorine contents. On the other hand, biosphere transfer factors values are issued from experimental studies adapted to Andra context: soil characteristics, climate, agricultural habits and species. These specific data are useful only if main factors controlling mobility have been determined previously for each radionuclide, which implicates good knowledge of environmental radionuclides behaviour. This site-specific approach allows to reduce uncertainty and range of variation of impact calculations and ensure a consistent model. It helps also to achieve scientific community approval by showing mastery of radionuclides environmental processes and public understanding by focusing demonstration on real local conditions. The methodology is fully presented. Two examples for uranium and chlorine and the limits of this approach are given.
\end{abstract}

\section{INTRODUCTION}

Andra designs, builds operates and supervises French radioactive waste disposals. The health impact assessment is the key point to demonstrate the safety of the installations. The impact is calculated with a model of transfer of radionuclides in the biosphere which uses a compartmental approach except for ${ }^{14} \mathrm{C}$, ${ }^{3} \mathrm{H}$ and ${ }^{36} \mathrm{Cl}$. Compartments are considered in equilibrium and linked together by some ways of transfers chosen to correspond to human radiological highest exposure (external exposure, inhalation and ingestion). Transfer factors values in the biosphere are often generic, issued from international compilation of experimental data measured on various environmental conditions whatever the site and the context. As recommended in the AIEA technical report series 364 [1] "Because of the variability which occurs from location to location in the world, it is stressed that the use of site specific data is always preferable to the use of generic values" and in BIOMASS Theme1 report, Andra has decided to adapt its biosphere transfer parameter values to its sites in order to reduce uncertainty in its model and to acquire a better knowledge of its sites. The purposes of this paper are to explain why and how Andra has led a true site-specific approach for the modelling of the radionuclides transfer in the biosphere. 


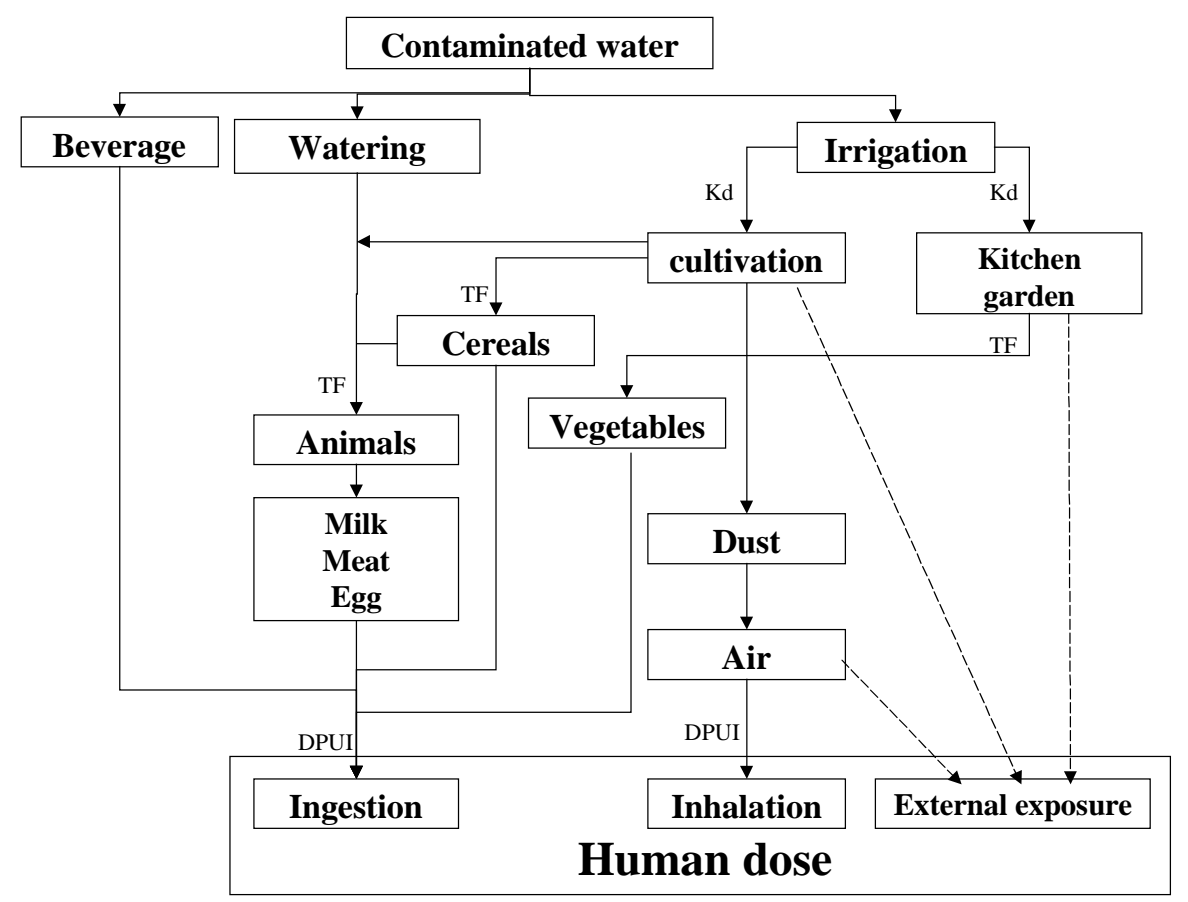

Figure 1. Majors ways of water transfer considered for radiological impact assessment. TF : transfer factor, ratio between radionuclides activity in compartment $\mathrm{i}+1$ and in compartment i.Kd: water/solid coefficient distribution : for a solid-liquid mixture, ratio between the concentration in radionuclides in the solid phase and in the liquid phase.

\section{DEFINITION OF THE SITE-SPECIFIC APPROACH}

The key idea of this approach is to adapt as close as possible the modelling to the site-conditions, by considering all the factors that can influence the values of transfer parameters as water/soil distribution coefficient or soil to plant transfer factor. This approach is based on the state of the art about the behaviour of radionuclides in the biosphere and all suitable measurements carried out around the site.

Many factors may influence transfer parameter values (Table 1). Most of the time one or a few of this factors really influence the mobility of the considered element. Once the influencing factors are determined, measuring theme on the site is the key of the site-specific approach.

Table 1. Factors controlling transfer parameter values.

\begin{tabular}{|l|l|}
\hline Soil & Factors \\
\hline Climate & $\begin{array}{l}\text { Soil granulation, organic matter, redox potential, concentration } \\
\text { in stable element, concentration in other element... }\end{array}$ \\
\hline Agronomic techniques & Temperature, pressure, ETP, humidity... \\
\hline Plants & $\begin{array}{l}\text { Soil conditioner }\left(\mathrm{NO}_{3}, \mathrm{~K}, \mathrm{Cl}\right), \text { ploughing, crop rotation, number of harvest } \\
\text { each year... }\end{array}$ \\
\hline Animals & Species, ripeness... \\
\hline
\end{tabular}




\section{JUSTIFICATION OF THE SITE-SPECIFIC APPROACH}

\subsection{Reducing uncertainty}

The main advantage of a site-specific approach is, of course, to reduce uncertainties on the impact calculations. When the site is known, values of parameters can be adapted. For example, if there is no precision about the soil, the soil/water partition coefficient value varies in a large range, including values for all types of soils (sand, loam, clay, organic), i.e. several orders of magnitude but when the type of soil is known, only values for this type will be considered, and, automatically, the uncertainty decreases.

\subsection{Scientists approval}

A site-specific approach require a good knowledge of radionuclides' behaviour and processes governing radionuclides transfers, so having such an approach shows that the modeller masters this knowledge. This is really important point because it arouse trust of the public and it allows to have the approval of the community of scientists.

\subsection{Public trust}

A real site-specific approach requires to achieve many elements such as climate, soils type, soil occupancy, habits of people, agronomic techniques and even some data specific to one radionuclide ( $\mathrm{pH}$ for $\mathrm{U}$ or Eh for Tc). If the site is really well described, the modelling will correspond to something real. When one explain to the public that the site has been very well studied, that the modelling fit as well as possible with the reality. The public will better accept the result than the one of a generic modelling.

\subsection{Consistency of the modelling}

The advantage of fitting to something real is that the modelling will be consistent. We will not use a $\mathrm{Kd}$ for a clay soil types and a soil-to-plant factor for a sand soil type, which is unfortunately possible when generic values are used.

\section{A METHODOLOGY FOR THE SITE-SPECIFIC APPROACH}

The model involves the use of one parameter for each of the 20 ways of transfer and for each of the 30 radionuclides taken into account, so 600 parameters should be studied. But each parameter does not have the same importance regarding the impact and it is important to fix how a value to each parameter must be given. So a methodology to select important parameters was elaborated.

Two different steps were defined, the first step is the choice of main radionuclides and the second step is the choice of main parameters for these radionuclides.

A radionuclide is a priority if it has a significant participation to the dose in previous Andra's calculation. A first set of radionuclides is selected. For high activity and long-lived radionuclides disposal, the main priority radionuclides are the following: ${ }^{14} \mathrm{C},{ }^{36} \mathrm{Cl},,{ }^{99} \mathrm{Tc},{ }^{126} \mathrm{Sn},{ }^{108 \mathrm{~m}} \mathrm{Ag},{ }^{129} \mathrm{I},{ }^{135} \mathrm{Cs}, \mathrm{U},{ }^{237} \mathrm{~Np}$.

When priority radionuclides are selected, the next step is to defined priority parameters for these radionuclides. A sensibility analysis was lead for each radionuclides . A Monte-Carlo method was used [2].

Table 2 shows the number of appearance as a priority parameter for each parameter. We can notice that the water/soil partition coefficient appears themost. 
Table 1. Priority parameter for short-lived low and intermediate level waste [6].

\begin{tabular}{|l|l|c|}
\hline \multicolumn{2}{|l|}{ Parameter } & $\begin{array}{c}\text { Number of appearance as a priority } \\
\text { parameter }\end{array}$ \\
\hline \multirow{4}{*}{ TF } & Fodder and water to lamb transfer & 0 \\
\cline { 2 - 3 } & Fodder and water to beef transfer & 0 \\
\cline { 2 - 3 } & Fodder and water to milk transfer & 1 \\
\cline { 2 - 3 } & Fodder and water to egg transfer & 0 \\
\cline { 2 - 3 } & Fodder and water to chicken transfer & 0 \\
\cline { 2 - 3 } & Fodder and water to pork transfer & 0 \\
\cline { 2 - 3 } & Soil to cereals transfer & 1 \\
\cline { 2 - 3 } & Soil to leafy vegetables transfer & 5 \\
\cline { 2 - 3 } & Soil to fruit transfer & 4 \\
\cline { 2 - 3 } & Soil to patatoes transfer & 6 \\
\cline { 2 - 3 } & Soil to root vegetables transfer & \\
\cline { 2 - 3 } & Soil to grass transfer & \\
\cline { 2 - 3 } & Transfer from water to plant via foliar absorption & \\
\hline \multirow{3}{*}{ Kd } & Water/soil distribution coefficient & \\
\cline { 2 - 3 } & Water / suspended particle distribution coefficient & \\
\hline
\end{tabular}

The methodology is summed up in a logigram (Figure 2).

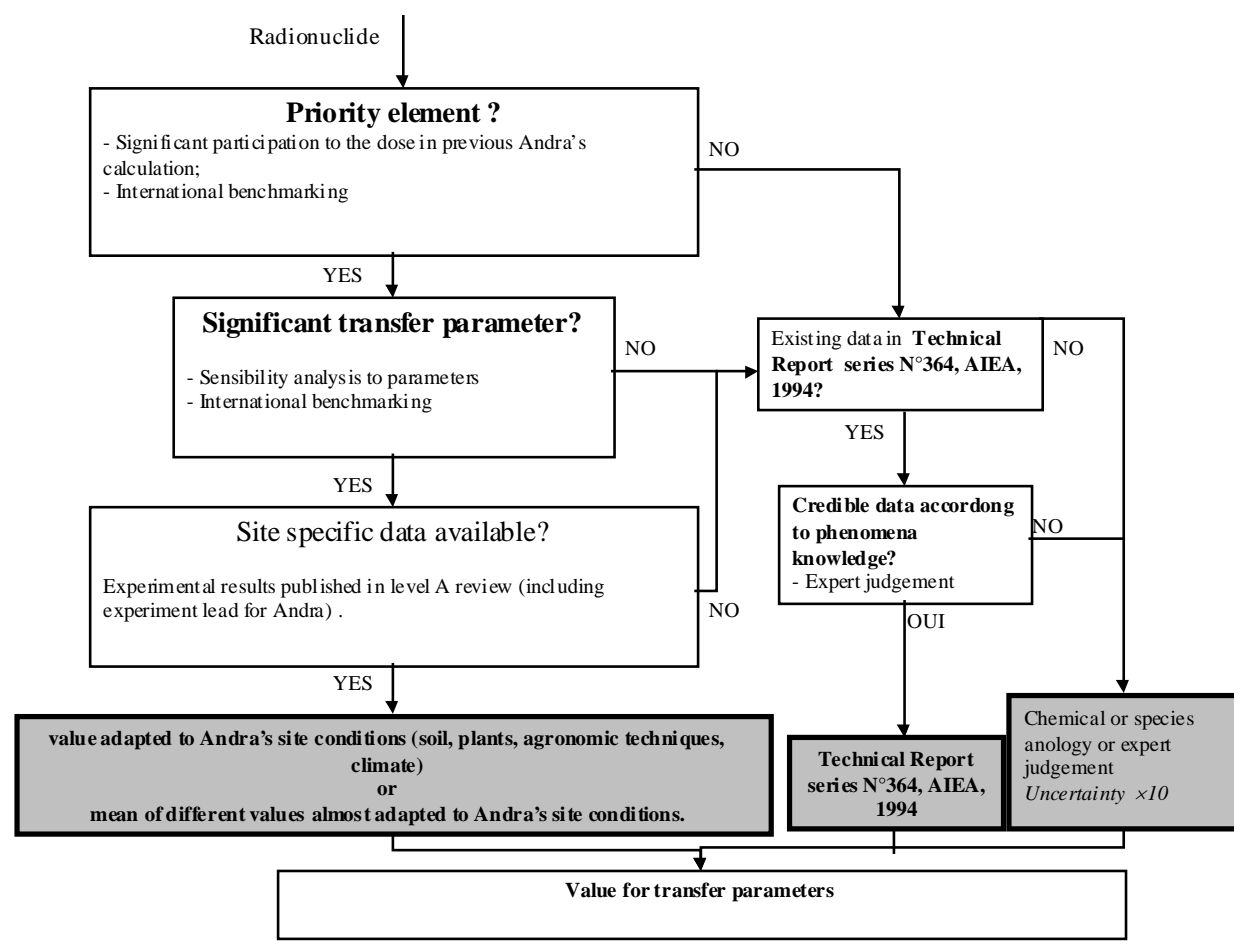

Figure 2. Logigram to select transfer parameter values for radionuclides.

\section{APPLICATION OF THE METHODOLOGY, SOME EXAMPLES OF SITE SPECIFIC VALUES}

\subsection{Uranium Kd and pH, Andra's study}

Andra asked and funded for a study on mobility of Uranium in different soils. The conclusion of this study was that the behaviour of Uranium in soil is closely linked to the $\mathrm{pH}$ of the soil. Uranium is highly sorbed at low $\mathrm{pH}$ : 


$$
\log (K d)=-1,25 \cdot p H+10,9\left(r^{2}=0,894 \text { and } n=13\right)
$$

This is a probable consequence of the existence of different uranium complexes at different $\mathrm{pH}$. The sorption behaviour differences between $\mathrm{UO}_{2}{ }^{2+}$ and $\mathrm{UO}_{2}\left(\mathrm{CO}_{3}\right)_{\mathrm{x}}{ }^{(2 \mathrm{x}-2)-}$ are so great that any other effect of soils properties on $U$ sorption is hidden.

Andra decided to use this formula for the different soil around its site. First a map of $\mathrm{pH}$ value was drawn (Figure 3).

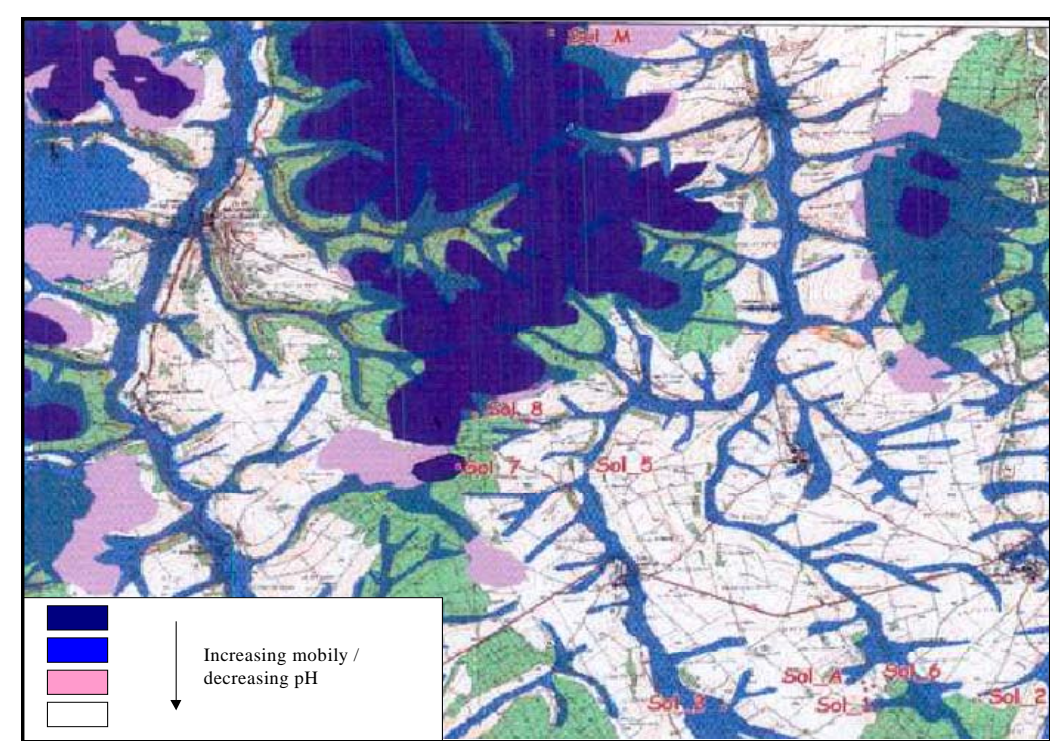

Figure 3. Map of mobility of U in soils around Meuse Haute-Marne URL Andra site.

The reference value was calculated as the mean of $\mathrm{pH}$ value founded for each soil unit (reference

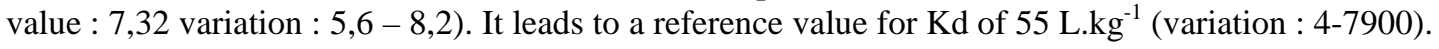
The uncertainty remains high but it is correlated to spatial variations of site $\mathrm{pH}$ (Figure 4).

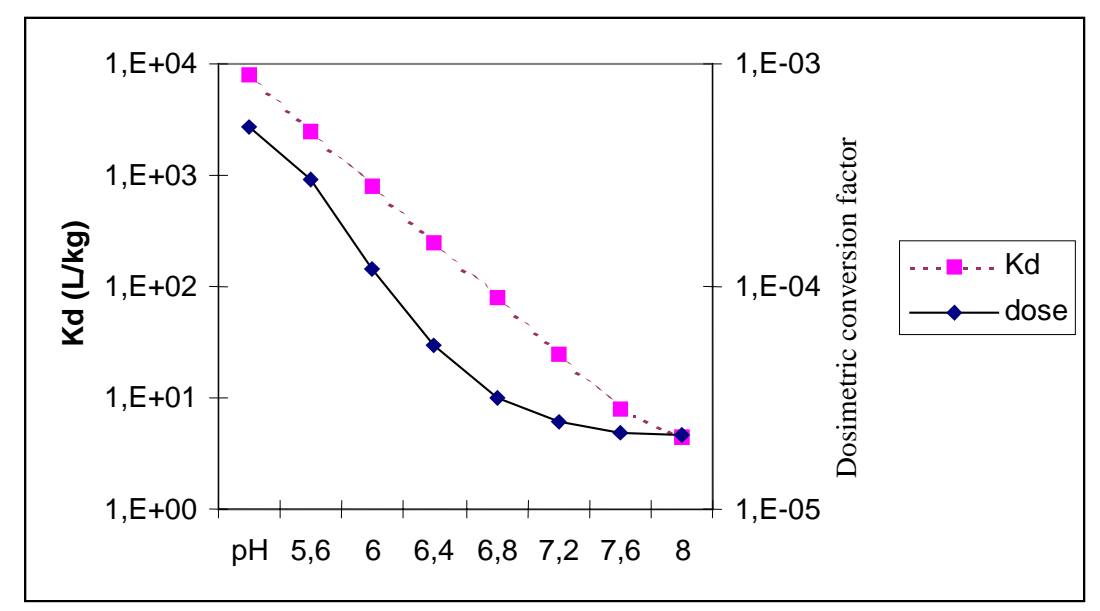

Figure 4. Variation of dosimetric conversion factor ((Sv/an)/(Bq/L)) and $\mathrm{Kd}$ with $\mathrm{pH}$ for $\mathrm{U}$ (the dosimetric conversion factor is defined as the annual dose to a human being for an activity of $1 \mathrm{~Bq} / \mathrm{L}$ at the interface geosphere biosphere zone). 


\section{$5.2{ }^{36} \mathrm{Cl}$ : measurements in the environment}

The modelling of the transfer of ${ }^{36} \mathrm{Cl}$ among the biosphere is based on the hypothesis that the behaviour of ${ }^{36} \mathrm{Cl}$ is the same as the one of stable chlorine and uses a specific activity model. In such model the main parameter is the concentration in stable chlorine of each compartment and, especially in water. So, Andra has measured this concentrations in rivers close to its sites in order to adapt the model (Figure 5).

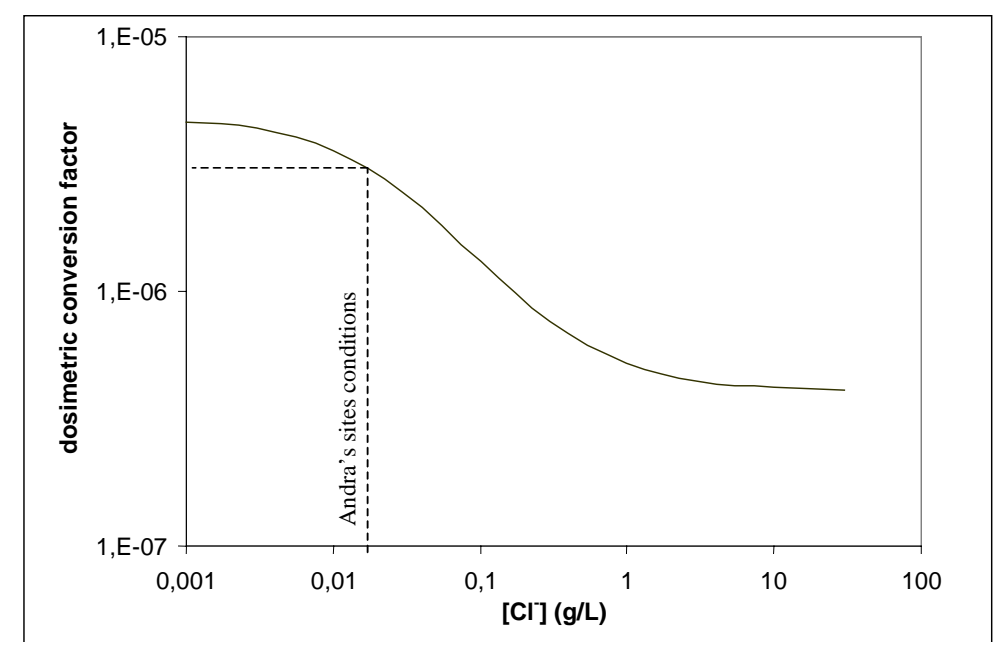

Figure 5. Influence of the concentration in $\mathrm{Cl}^{-}$in the river on the dosimetric conversion factor ((Sv/an)/Bq/L)).

\section{CONCLUSION}

The site-specific approach may seems heavy to lead regarding the pros and cons and may not be applicable on long period of time because of its accuracy. But it is the better solution for the waste disposal agency to understand what really happen in the biosphere and the real impact of the disposal. More, this approach is reassuring for the public and shows him that we have really studied his environment and it arrows the approval of the scientist community. Last, as we dot not know the evolution of site in the next one million years, a safety demonstration considering well-known actual site-conditions may seem as valuable as any other approach.

\section{References}

[1] AIEA (1994). Handbook of Parameter Values for the Prediction of Radionuclide Transfer in Temperate Environments. Vienna, AIEA.

[2] Helton, J. C. (1993). "Uncertainty and sensivity analysis techniques for use in performance assessment for radioactive waste disposal." Reliability Engineering and System Safety $\mathbf{4 2 .}$

[3] Saltelli, A., T. H. Andres, et al. (1991). "Sensivity analysis of model output. An investigation of new techniques." Computational Statistics and Data Analysis $\mathbf{1 5 .}$

[4] Saltelli, A. and J. Marivoet (1990). "Non-parametric statistics in sensivity analysis for model output: a comparison of selected techniques." Reliability Engineering and System Safety.

[5] Sheppard, M. I., D. I. Beals, et al. (1984). "Soil nuclide distribution coefficients and their statistical distributions." Report Number: AECL-8364: pages.

[6] Albrecht, A. (2002). "Centre de l'aube. Analyse de sensibilité des paramètres affectant le comportement des radionucléides pour le rapport de sûreté 2004." SUR NT ASTR 02-095. 
[7] Echevarria, G., M. I. Sheppard, et al. (2001). "Effect of pH on the sorption of uranium in soils." Journal of Environmental Radioactivity 53(2): 257-264.

[8] Echevarria, G., P. C. Vong, et al. (1995). Availability of 99Tc to Rye-grass grown on agricultural soils. Symposium IAEA-FAO, Vienne.

[9] Nisbet, A. F. and R. F. M. Woodman (2000). "Soil-to-plant transfer factors for radiocesium and radiostrontium in agricultural systems." Health Phys. 78(3): 279-288.

[10] Echevarria, G., P. C. Vong, et al. (1997). "Bioavailability of Technetium-99 as affected by plant species and growth, application form and soil incubation." Journal of Environmental Quality 26(4).

[11] Sheppard, S. C., M. I. Sheppard, et al. (1990). "A novel method used to examine variation in ${ }^{99}$ Tc sorption among 34 soils, aerated and anoxic." J. Environ. Radioactivity 11: 215-233.

[12] Echevarria, G., P. C. Vong, et al. (1996). "Effect of $\mathrm{NO}_{3}{ }^{-}$on the fate of ${ }^{99} \mathrm{TcO}_{4}{ }^{-}$in the soil-plant system." J. Environ. Radioactivity 38(2): 163-171.

[13] Morel, R. (1996). Les sols cultivés, TEC \& DOC. 